\title{
Hauke Brunkhorst e o conceito de solidariedade democrática como crítica à esfera pública pós-nacional de Jürgen Habermas
}

\author{
Hauke Brunkhorst and the concept of democratic \\ solidarity as criticism to Jürgen Habermas' \\ post-national public sphere
}

*Jorge Adriano Lubenow

\begin{abstract}
Resumo: O artigo trata da reformulação do conceito de esfera pública habermasiano por parte de Hauke Brunkhorst. Visa a reconstruir essa crítica e elucidar a contraproposta de esfera pública a partir do conceito de solidariedade democrática. Para Brunkhorst, o conceito de esfera pública, tal como entendido por Habermas para o âmbito europeu e global, seria insuficiente para compreender as constelações políticas pós-nacionais globalizadas. A vantagem seria fornecer um conceito de esfera pública mais flexível e menos fechado ao âmbito institucional.
\end{abstract}

Palavras-chave: Hauke Brunkhorst, Jürgen Habermas, esfera pública, democracia solidária.

\begin{abstract}
This essay is about the reformulation of Habermas' concept of public sphere by Hauke Brunkhorst. It aims to rebuild this critic and to elucidate the counterproposal of public sphere from the concept of democratic solidarity. For Brunkhorst, the concept of public sphere, such as extended by Habermas to European and global context, would be insufficient to understand the globalized postnational political constellations. The advantage would be to provide a more flexible and less tight concept of public sphere to the institutional framework.

Keywords: Hauke Brunkhorst, Jürgen Habermas, public sphere, democratic solidarity.
\end{abstract}

* Professor Adjunto do DFE e Professor Permanente do Mestrado em Filosofia da UFPB, João Pessoa, Brasil. Endereço Postal: Programa de Pós-Graduação em Filosofia - UFPB. Centro de Ciências Humanas, Letras e Artes - Coordenação do Programa de PósGraduação em Filosofia - Campus I, Bloco Humanístico - Cidade Universitária - João Pessoa, PB - CEP 58059-900. <jlubenow@hotmail.com>

\begin{tabular}{|l|l|l|l|l|l|}
\hline Veritas & Porto Alegre & v. 58 & n. 1 & jan./abr. 2013 & p. 118-130 \\
\hline
\end{tabular}




\section{Introdução}

Vários são os discursos críticos que emergem do contexto alemão em relação à categoria de esfera pública de Jürgen Habermas. Por sua maior proximidade com a tradição temática da teoria crítica, podemos citar as reconstruções críticas de Hauke Brunkhorst ${ }^{1}$ e Axel Honneth. ${ }^{2}$ Além disso, podemos citar as discussões de Lutz Wingert e Klaus Günther, ${ }^{3}$ Peter Niesen e Benjamim Herbot, ${ }^{4}$ Bernadr Peters, ${ }^{5}$ Ralf Hemming,${ }^{6}$ Peter Hohendahl, ${ }^{7}$ Matin Scheyli, ${ }^{8}$ Lennart Labarenz, ${ }^{9}$ Friedhelm Neidhadrt, ${ }^{10}$ Gerhard Göhler ${ }^{11}$ e Rainer Forst. ${ }^{12}$ No entanto, apesar da bibliografia crítica indicada, interessam, aqui, apenas a controvérsia que emerge dos discursos críticos acerca das possibilidades de uma esfera pública pósnacional, particularmente nas obras de Hauke Brunkhorst. A ênfase, aqui, é a reformulação da noção habermasiana de esfera pública pós-nacional elaborada por Hauke Brunkhorst, Professor de Filosofia e Sociologia da Universität Flensburg, Alemanha. ${ }^{13}$

1 Ver, por exemplo, as obras: Habermas. Reclam, 2006; Adorno and Critical Theory. University of Wales Press, 1999; Herbert Marcuse. Junius, 1990.

2 Para uma síntese do argumento central da crítica de Honneth a Habermas, ver: Lubenow, As críticas de Axel Honneth e Nancy Fraser à filosofia política de Jürgen Habermas, In: Veritas - Revista de Filosofia (PUCRS), 55(1), 2010, p. 121-134. Para leitura dos textos originais: Honneth, Kritik der Macht. Suhrkamp, 1985; Honneth, Kampf und Anerkennung. Suhrkamp, 1992; Honneth, Leiden an Unbestimmtheit. Suhrkamp, 1992; Honneth, Verdinglichung. Eine anerkennungstheoretische Studie. Suhrkamp, 2005; Honneth, Pathologien der Vernunft. Geschichte und Gegenwart der Kritischen Theorie. Suhrkamp, 2007; Honneth, Disrespect: the normative foundations of critical theory. Polity Press, 2007; Honneth \& Fraser, Umverteilung oder Anerkennung? Eine politischphilosophische Kontroverse. Suhrkamp, 2003.

3 Wingert \& Günther, Die Öffentlichkeit der Vernunft und die Vernunft der Öffentlichkeit. Suhrkamp, 2001.

4 Niesen \& Herborth, Anarchie der kommunikativen Freiheit. Jürgen Habermas und die Theorie der internationalen Politik. Suhrkamp, 2007.

5 Peters, Der Sinn von Öffentlichkeit. Suhrkamp, 2007.

6 Heming, Öffentlichkeit, Diskurs und Gesellschaft. Zum analytischen Potential und zur Kritik des Begriffs der Öffentlichkeit bei Habermas. Deutscher Universität Verlag, 1997.

7 Hohendahl, Öffentlichkeit, Geschichte eines kritischen Begriffs. Metzler Verlag, 2000.

8 Scheyli, Politische Öffentlichkeit und Deliberative Demokratie nach Habermas. Nomos, 2000.

9 Laberenz, Schöne neue Öffentlichkeit. Beiträge zu Jürgen Habermas "Strukturwandel der Öffentlichkeit". VSA-Verlag, 2003.

10 Neidhardt, Öffentlichkeit, öffentliche Meinung, soziale Bewegung. Westdeutschland Verlag, 1994.

11 Göhler, Macht der Öffentlichkeit - Öffentlichkeit der Macht. Nomos, 1995.

12 Forst, Kontexte der Gerechtigkeit. Suhrkamp, 1996; Toleranz im Konflikt, Suhrkamp, 2003.

13 Especialmente: Legitimationskrisen. Verfassungsprobleme der Weltgesselschaft. Nomos, 2012; Habermas. Reclam, 2006; Solidarität. Von der Bürgerfreundschaft zur globalen Rechtsgenossenschaft. Suhrkamp, 2002 [Trad. ingl.: Solidarity. From Civic Friendship to a Global Legal Community. Cambridge/London: MIT Press, 2005]; Jenseits von Zentrum 
Ainda pouco conhecido no Brasil, Brunkhorst é autor de uma consistente e extensa produção bibliográfica, na qual busca reformular o conceito de esfera pública tal como estendido por Habermas para o âmbito europeu e global, mas que seria insuficiente para compreender as constelações políticas pós-nacionais globalizadas. A categoria de esfera pública deliberativa não proveria uma perspectiva analítica apropriada para analisar procedimentos deliberativos na esfera pós-nacional. Nesse sentido, o conceito-chave a partir do qual é possível reconstruir a crítica e elucidar a proposta de Brunkhorst é o de "solidariedade democrática".

\section{A esfera pública pós-nacional em Jürgen Habermas}

A categoria de esfera pública é central na configuração do pensamento político de Jürgen Habermas. ${ }^{14}$ No entanto, é possível identificar, nos escritos políticos de Habermas posteriores à obra Faktizität und Geltung (1992), o deslocamento da tematização da esfera pública para o âmbito pós-nacional ou global (Weltöffentlichkeit). Nestes escritos sobre a esfera pública posteriores a obra sobre direito e democracia, ${ }^{15}$ Habermas retoma e busca elucidar as controvérsias acerca da esfera pública e da política deliberativa, a relação entre esferas informais do mundo da vida e as esferas formais do sistema político institucionalizado, e o modo como, no seu bojo, articula-se essa mediação. Esta tentativa de melhor esclarecer a articulação entre a autocompreensão normativa do estado de direito e

und Peripherie. Zur Verfassung der fragmentierten Weltgesellschaft. Rainer Hampp, 2005; Globalisierung und Demokratie. Wirtschaft, Recht, Medien. Suhrkamp, 2000; Recht auf Menschenrecht. Menschenrechte, Demokratie und Internationale Politik. Suhrkamp, 1999; Demokratischer Experimentalismus. Politik in der komplexen Gesellschaft. Suhrkamp, 1998.

14 Sobre o tema da esfera pública nos escritos políticos de Habermas, ver: Lubenow, $A$ categoria de esfera pública em Jürgen Habermas: para uma reconstrução da autocrítica. João Pessoa: Editora Manufatura, 2012. Sobre alguns discursos críticos, ver: Lubenow, Esfera pública e democracia deliberativa em Habermas: modelo teórico e discursos críticos, in Kriterion - Revista de Filosofia (UFMG), n.121, 2010, p. 227-258; Lubenow, A esfera pública 50 anos depois: esfera pública e meios de comunicação em Jürgen Habermas, in Transformação - Revista de Filosofia (UNESP), 35(3), 2012, p. 189220; Lubenow \& Silva, Dossiê esfera pública 50 anos depois. Problemata - Revista Internacional de Filosofia (UFPB), 3(2), 2012.

15 Mesmo já a partir dos "Estudos Preliminares e Complementos" e no "Posfácio" à quarta edição de Faktizität und Geltung (de 1994), na entrevista "Faktizität und Geltung. Ein Gespräch über Fragen der politischen Theorie" em Die Normalität einer Berliner Republik (1995), e de modo mais incisivo nas obras Die Einbeziehung des Anderen (1996, especialmente o "Apêndice a 'Faktizität und Geltung'"), Die postnationale Konstellation (1998), Zeit der Übergange (2001), Zeitdiagnose (2003), Der Gespaltene Westen (2004), Zwischen Naturalismus und Religion (2005), Ach, Europa (2008) e Zur Verfassung Europas (2012). 
a facticidade dos processos políticos já se movimenta sob um modificado pano de fundo teórico da esfera pública: o contexto pós-nacional.

Nesse sentido, as discussões habermasianas sobre as possibilidades práticas do modelo deliberativo de esfera pública foram aos poucos sendo estendidas para o campo político pós-nacional, uma esfera pública deliberativa pós-nacional. Especialmente a partir de Die Einbeziehung des Anderen (1996), são tematizadas novas questões envolvendo a esfera pública pensada, agora, num âmbito pós-nacional, no qual se inscrevem novos problemas envolvendo a relação entre autonomia pública e privada, entre soberania popular e direitos humanos, entre democracia e Estado de direito, a ampliação da esfera de influência das sociedades democráticas para além das fronteiras nacionais, os desafios da democracia numa constelação pós-nacional, os limites e a superação do Estado nacional, as possibilidades e aporias resultantes da transição de uma clássica política do poder para uma sociedade cosmopolita, o problema da legitimidade democrática do ordenamento político internacional, a crise de legitimidade e do déficit democrático da União Europeia, entre outros. ${ }^{16}$

A reorientação habermasiana para um âmbito temático pós-nacional visa a discutir as possibilidades e formas de um projeto constitucional de um estado democrático e de democracia deliberativa que envolvam a esfera pública no nível global. Habermas parte do princípio de que os Estados nacionais não conseguem mais dar conta dos problemas de legitimação da política (ou dos efeitos colaterais de outras esferas de ação, como a economia), decorrentes da movimentação transnacional do capital financeiro, e que acaba afetando, de uma forma ou de outra, os mecanismos de legitimação institucionalizados nos Estados nacionais. A expansão do debate sobre a esfera pública para um âmbito global (Weltöffentlichkeit) significa que o contexto teórico específico que, até

${ }_{16}$ Especialmente em: Die postnationale Konstellation (1998), Zeit der Übergange (2001), Der Gespaltene Westen (2004), Ach, Europa (2008) e Zur Verfassung Europas (2012). Embora seja secundária aqui, a esfera pública recebe destaque nos escritos habermasianos também: a) na autocompreensão pós-metafísica da Modernidade, pela emergência de duas tendências contrárias que caracterizam a época atual, a saber, a proliferação de imagens de mundo naturalistas e a influência política crescente das ortodoxias religiosas - especialmente, as controvérsias sobre o papel político da religião discussão desdobrada nos temas do pluralismo religioso, secularismo, multiculturalismo, fundamentalismo, tolerância, solidariedade, identidade coletiva e nacionalismo, especialmente em Zwischen Naturalismus und Religion, 2005, cap. 5); e b) A discussão de Habermas com as abordagens empíricas, que visam a examinar criticamente a viabilidade empírica (instrumentalização, operacionalização) da esfera pública deliberativa, conforme Habermas, Concluding comments on empirical approaches to deliberative politics, in Acta Politica. International Journal of Political Science, 40(3), Set/2005, p. 384-392; Habermas, Ach Europa, 2008, Parte III: "Zur Vernunft der Öffentlichkeit". 
aqui, serviu de base para a discussão e descrição das possibilidades de uma esfera pública - cultura política comum engenhada no âmbito territorial nacional, Estado-nação ou a autoridade do estado como endereço político do público, soberania popular, estado democrático de direito, constituição, direito -, já não era suficiente para compreender a nova dinâmica engendrada pelo processo de globalização do capital e da política em termos internacionais, ou as repercussões em escala mundial como a queda do socialismo de estado nos países do leste europeu que engendraram novas experiências de democratização, o movimento feminista crescente em termos mundiais e os movimentos de democratização na China e na África. Nesta perspectiva, uma esfera pública pós-nacional seria uma arena mais adequada para a tematização de problemas relevantes comuns e para fornecer uma melhor solução aos atuais problemas de legitimação enfrentados pelas instâncias normativas legais internacionais institucionalizadas.

No entanto - e aqui centra-se a crítica de Brunkhorst -, o conceito de esfera pública, tal como estendido por Habermas, para além das interações simples do contexto nacional e que se configuram num contexto de aplicação mais amplo, mais complexo e mais pluralista do âmbito europeu e global, seria insuficientemente institucionalizado como mecanismo de solução de problemas e resolução de conflitos nesse nível das constelações políticas pós-nacionais globalizadas. Neste caso, a categoria de esfera pública deliberativa não seria um instrumental capaz de conciliar a necessidade de participação e de procedimentos deliberativos em contextos de interação social que exibem um incremento impressionante no volume da comunicação política e que precisa lidar com dimensões tão ampliadas da esfera pós-nacional; não seria capaz de operacionalizar a interconexão entre as esferas do mundo da vida situadas localmente com processos de comunicação pública a nível global. ${ }^{17}$

17 O próprio Habermas chega a indicar falhas evidentes nos procedimentos deliberativos de uma esfera pública política, no nível internacional, dominada por uma comunicação pública mediada pelos meios de comunicação de massa e estruturas de poder, uma vez que as dinâmicas de comunicação de massa são dirigidas pelo poder seletivo da mídia e pelo uso estratégico do poder social e político para influenciar a triagem e o estabelecer da agenda dos assuntos públicos (Habermas, Political communication in media society, p. 10). Ainda nesse sentido, o próprio Habermas compartilha com Cohen e Arato uma certa dose de ceticismo em relação às possibilidades oferecidas pelas esferas públicas tradicionais dominadas pelo poder e pelos meios de comunicação de massa, pois o modo de operar destes meios na elaboração de estratégias e mecanismos de comunicação acaba afetando a esfera pública, diminuindo o nível discursivo da circulação pública da comunicação. Esta "submissão" é a maior preocupação compartilhada por Habermas também com a Sociologia da Comunicação (Habermas, Faktizität und Geltung, p. 455-458). 


\section{A reformulação do conceito de esfera pública em Hauke Brunkhorst}

O pensamento social e político de Hauke Brunkhorst dirige-se a uma teoria política normativa internacional e insere-se na linha teórica da democracia deliberativa. O conceito normativo central é "solidariedade democrática". ${ }^{18}$ A formulação de uma teoria da democracia solidária tenta superar o modelo de democracia liberal. O pano de fundo é que deliberação pública e procedimentos para legitimar decisões políticas são (ou podem ser) guiados pelo "uso público da razão". Diferente do modelo liberal, que agrega preferências e interesses através do voto da maioria, o modelo deliberativo tem o potencial de transformar preferências à luz da deliberação pública, e os efeitos da discussão democrática sobre os processos de decisão políticos. No entanto, como esta proposta pode ser institucionalizada, se o ideal de deliberação "presencial" não encontra mais lugar nas sociedades modernas, caracterizadas pela complexidade social e pluralismo cultural? Para o ex-Theodor Heuss Professor at the New School for Social Research, Estados Unidos, nos anos de 2009 e

18 Para o conceito de "solidariedade", ver Brunkhorst, Solidarität, 2002, p. 9-20. (Trad. ingl.: Solidarity. From Civic Friendship to a Global Legal Community. Cambridge/ London: MIT Press, 2005). Para citar algumas obras de Brunkhorst: (ed.) Demokratie und Differenz. Vom klassischen zum modernen Begriff des Politischen. Fischer, 1994; (ed.) Gemeinschaft und Gerechtigkeit. Fischer, 1995; Solidarität unter Fremden. Fischer, 1997; (ed.) Demokratischer Experimentalismus. Politik in der komplexen Gesellschaft. Suhrkamp, 1998; (ed.) (ed) Recht auf Menschenrecht. Menschenrechte, Demokratie und Internationale Politik. Suhrkamp, 1999; (ed.) Das Recht der Republik. Suhrkamp, 1999; Globalisierung und Demokratie. Wirtschaft, Recht, Medien. Suhrkamp, 2000; Solidarität. Suhrkamp, 2002; (ed.) Peripherie und Zentrum in der Weltgeselschaft. Rainer Hampp Verlag, 2004; (ed.) Jenseits von Zentrum und Peripherie. Zur Verfassung der fragmentierten Weltgesellschaft. Rainer Hampp Verlag, 2005; Völkerrechtspolitik. Recht, Staat und Internationale Gemeinschaft im Blick auf Kelsen. Liszt Verlag, 2006; Habermas. Reclam, 2006; \& Cristina Lafont/Regina Kreide, Habermas-Handbuch: Leben, Werk, Wirkung, Metzler, 2009. Além disso, ver: Brunkhorst, Globale Solidarität: Inklusionsprobleme der modernen Gesellschaft, in L. Wingert (ed). Die Öffentlichkeit der Vernunft und die Vernunft der Öffentlichkeit. Festschrift für Jürgen Habermas. Suhrkamp, 2001, p. 605-626; Globalising Democracy Without a State: Weak Public, Strong Public, Global Constitutionalism, in Millenium - Journal of International Studies 31, 2002, p. 675-690; Demokratie in der Weltgesellschaft. Hegemoniales Recht, schwache Öffentlichkeit, Menschenrechtspolitik, in Bloch-Jahrbuch, 2003, p. 147-162; Bürgerschaftliche Solidarität im Prozess der Globalisierung - eine bildungstheoretische Perspektive, in Steffens \& Weiß (ed). Jahrbuch für Pädagogik 2004. Globalisierung und Bildung. Frankfurt: Europäischer Verlag der Wissenschaften, 2004, p. 99-112; Demokratie in der globalen Rechtsgenossenschaft - Einige Überlegungen zur poststaatlichen Verfassung der Weltgesellschaft, in: Sonderheft Weltgesellschaft der Zeitschrift für Soziologie, (2005); Demokratie als globales Projekt, in Demokratiekompetenz. Beiträge aus Politikwissenschaft, Pädagogik und politischer Bildung. Himmelmann \& Lange (ed) Wiesbaden: Verlag für Sozialwissenschaften, 2005, p. 100-113; Demokratie in der globalen Rechtsgenossenschaft. Einige Überlegungen zur poststaatlichen Verfassung der Weltgesellschaft, in Zeitschrift für Soziologie: Sonderheft Weltgesellschaft, 2005. 
2010, a esfera pública é, aqui, fundamental como um locus de deliberação nas sociedades modernas, e, sobre a esfera pública global, emergindo como um espaço para desenvolver legitimidade democrática para além do estado-nação.

Seguindo Habermas e Nancy Fraser, Brunkhorst distingue entre esfera pública "forte" e "fraca". ${ }^{19}$ Uma esfera pública seria "fraca" quando deliberações compartilham opiniões, mas não têm o poder de tomar decisões políticas (isso inclui comunicação e deliberação que toma lugar através dos novos mídias, que são desenvolvidos por organizações não-governamentais na sociedade civil). E a esfera pública seria "forte" quando está autorizada a tomar e vincular todas as decisões e tomar decisões políticas, parlamentos e legislaturas cujas deliberações resultam em decisões administrativas estatais.

No entanto, Brunkhorst quer tornar esse modelo de esfera pública "forte" endossado por Habermas "mais flexível" e menos fechado ao aparato institucional dos estados-nação, definindo uma esfera pública forte não estritamente pela sua capacidade de tomar decisões políticas institucionalizadas. Segundo o ex-aluno de Habermas,

Onde há uma constituição normativamente efetiva, cada esfera pública autônoma é um público forte, bem como ela não exclui alguém do discurso e contribui para vincular decisões de modo legalmente seguro. Todos debates públicos que são garantidos pelos direitos básicos, e que se cruzam com as decisões políticas das pessoas ou de seus representantes através de normas procedimentais e organizacionais da constituição, são fortes. ${ }^{20}$

A constituição efetiva normativamente precisa considerar os aspectos-chave dos direitos básicos e das normas procedimentais e poder organizacional. Nessa perspectiva, uma esfera pública forte pode ser estabelecida pelos direitos de participação juntamente com um modo de garantia formal constitucional para que deliberações públicas contribuam para a tomada de decisão. $\mathrm{E}$ a tentativa de institucionalização desses dois aspectos de uma constituição, no nível global, é o fio condutor da teoria política normativa do professor Brunkhorst.

Para estabelecer processos de deliberação e tomada de decisões legítimas no nível da política global, é fundamental atentar para o princípio da inclusão (tanto por razões normativas, quanto por razões epistêmicas). Para Brunkhorst, os processos de diferenciação funcional das sociedades modernas levaram ao estrutural problema de inclusão e sua solução requer

19 Brunkhorst, Solidarität, p. 184-5.

20 Brunkhorst, Solidarität, p. 185. 
o desenvolvimento de recursos normativos da "democracia solidária". A questão que surge é se o potencial de solidariedade das democracias modernas seria suficiente para resolver, agora, no nível da sociedade global, o retorno dos problemas que, certa vez, podia ser resolvido numa estrutura regional de estados-nação europeus.

Para Brunkhorst, a globalização unilateral do poder, lei e dinheiro não engendrou uma correspondente globalização da solidariedade democrática. A tese de Brunkhorst é que não há solução sem globalização da solidariedade democrática ${ }^{21} \mathrm{~A}$ solidariedade global não seria possível sem o desenvolvimento de formas democráticas de governança para além das fronteiras dos estados-nação. E, aqui, o autor também ensaia possibilidades de desenvolver formas de governo pós-nacional e além-Europa. ${ }^{22} \mathrm{O}$ pano de fundo é desenvolver uma solidariedade democrática em nível global dentro de uma comunidade global gerida pelo direito. ${ }^{23}$ No entanto, apesar deste pano de fundo teórico, o tema da solidariedade não é analisado apenas sob o ponto de vista normativo. Ao combinar perspectivas teóricas afins, como a teoria normativa com a sociologia política, Brunkhorst ensaia também uma perspectiva mais prática e a possibilidade de se desenvolverem formas mais concretas de solidariedade democrática. $^{24}$

${ }^{21}$ Cf. Brunkhorst, Solidarität, "Vorbemerkung", p. 8.

22 Essa questão do "retorno" é particularmente interessante se pensarmos em termos de Brasil. Acontece que, no Brasil, ainda não alcançamos o estágio da solução dos problemas de igualdade social, material. Até agora, a igualdade dá-se apenas em termos formais, legais. Assim, é preciso lidar com os problemas de inclusão, agora, sob o duplo aspecto: o aspecto da inclusão social, material, ainda não resolvido em termos de estado-nação (aliás, longe disso), e com os efeitos dos novos problemas de exclusão e de outra ordem que surgem em nível global e que nos afetam.

${ }^{23}$ Cf. parte III: "Solidarität in der globalen Rechtsgenossenschaft", p. 139-236. Nesse sentido, ver ainda: Brunkhorst, Recht auf Menschenrecht. Menschenrechte, Demokratie und Internationale Politik. Suhrkamp, 1999; Das Recht der Republik. Suhrkamp, 1999; Globalisierung und Demokratie. Wirtschaft, Recht, Medien. Suhrkamp, 2000; Jenseits von Zentrum und Peripherie. Zur Verfassung der fragmentierten Weltgesellschaft. Rainer Hampp, 2005; Internationale Verrechtlichung und Demokratie. Zum 60. Geburstag von Hauke Brunkhorst. Frankfurt, 2006; Verrechtlichung der Souveränität. Hans Kelsens Rechts- und Staatsverständnis. Nomos, 2006; Völkerrechtspolitik. Recht, Staat und Internationale Gemeinschaft im Blick auf Kelsen. Liszt, 2006.

24 Ver, por exemplo: Brunkhorst, Demokratischer Experimentalismus. Politik in der komplexen Gesellschaft. Suhrkamp, 1998; Recht auf Menschenrecht. Menschenrechte, Demokratie und Internationale Politik. Suhrkamp, 1999; Das Recht der Republik. Suhrkamp, 1999; Globalisierung und Demokratie. Wirtschaft, Recht, Medien. Suhrkamp, 2000. Estas obras contém contribuições importantes no que diz respeito a experiências democráticas analisadas ou desenvolvidas nos mais diversos contextos, seja da política, do direito, dos mída, da economia, da esfera pública, entre outros. 


\section{A democracia solidária em Hauke Brunkhorst}

O livro Solidarität é o que melhor sintetiza os principais eixos temáticos desenvolvidos por Brunkhorst. ${ }^{25}$ Nesta obra, encontramos, de início, uma explicação histórica do desenvolvimento da moderna ideia de solidariedade democrática, em contraposição a noções menos igualitárias da tradição greco-romana e judaico-cristã (Brunkhorst usa o termo "estágios"/Stufen). ${ }^{26}$ Por conseguinte, o autor analisa o processo de modernização das sociedades ocidentais, que teria destruído antigas formas de solidariedade baseadas nas estruturas hierárquicas das sociedades pré-modernas. Este processo fez surgir problemas de exclusão que apenas poderiam ser resolvidos pelas sociedades modernas com a ajuda da ideia de solidariedade democrática. Constituições democráticas transferem as forças sociais para um controle de uma comunidade constituída politicamente e, nesse sentido, servem para a incorporação institucional da solidariedade democrática. Um histórico potencial de resolução de problemas que somente pode ser resolvido pela autocompreensão das sociedades separadas funcionalmente. ${ }^{27} \mathrm{E}$, por fim, Brunkhorst analisa os problemas como inclusão, participação, solidariedade, democracia, entre outros, no nível das sociedades modernizadas globalmente.

Para Brunkhorst, a democracia moderna proveu, por ela mesma, a solução de problemas de inclusão que a sociedade não pode resolver por si mesma. Um problema (a) era o da separação socialmente produzida entre indivíduo e sociedade, e para o qual democracia é uma resposta prática para a diferenciação das atomizadas consciências separadas e que, agora, são constituídos, via comunidade social, como indivíduos. Outro problema (b) era a questão social, para o qual democracia provê, normativa e funcionalmente, uma solução para problemas de exclusão social. Somente através da inclusão política (ampliação dos direitos eleitorais, sufrágio universal, etc...), pode ser resolvido o problema da pauperização das classes trabalhadoras, por um lado, dependentes, mas, por outro lado, excluídas da socialização dos resultados do modo de produção capitalista.

Não obstante, a solução da democracia de massa igualitária permaneceu limitada à Europa e América do Norte, e estava vinculada

25 Brunkhorst, Solidarität. Suhrkamp, 2002.

${ }^{26}$ Cf. parte I: "Stufen der Solidarität", p. 21-110.

${ }^{27}$ Cf. parte II: „Sozialintegration ohne Solidarität“, p. 111-138. Sobre a transição de conceito clássico para o moderno de solidariedade, ver ainda: Brunkhorst, Demokratie und Differenz. Vom klassischen zum modernen Begriff des Politischen. Fischer; Solidarität unter Fremden. Fischer, 1997; Einführung in die Geschichte politischer Ideen. UTB, 2000. 
à forma política dos estados-nação. Acontece que as sociedades diferenciadas funcionalmente têm se globalizado totalmente. E, com isso, também os problemas de inclusão da modernidade europeia têm se globalizado. Não existe nenhum lugar, mercado de trabalho ou sistema de educação, que não seja afetado, de uma forma ou de outra, ou que não sinta os efeitos excludentes (Exklusioneffekte), que se reforçam pelos meios, autônomos, da ciência, do direito, da política mundial, entre outros.

O primeiro aspecto trata da socialização do indivíduo: como os indivíduos podem ser integrados na sociedade ${ }^{28}$ A resposta dá-se com a inclusão política (por exemplo: ampliação dos direitos eleitorais, sufrágio universal). O segundo aspecto trata da exclusão social, da exclusão da população dos ganhos da sociedade diferenciada funcionalmente (por exemplo: pauperização, proletarização). A resposta dá-se, depois de movimentos revolucionários e sociais do século XIX e XX, pela inclusão dos direitos sociais (modelos de social-democracia na Europa e alguns outros países, como os Estados Unidos). No entanto, essa solução deuse no âmbito do estado-nação. Hoje, de outro modo, presencia-se o retorno de problemas de inclusão, agora, no nível da sociedade global. Globalização que provoca mudanças econômicas, sociais, políticas e culturais, resultados de um mundo cada vez mais interconectado. Aspectos como o incremento dos fluxos de capital, bens e pessoas além fronteiras, a emergência e o incremento de corporações multinacionais, o declínio do poder do estado-nação em relação a políticas e forças econômicas externas, a homogenização da cultura popular global, são apenas algumas tendências que incrementam as inseguranças que tomam formas globais (fundamentalismos, catástrofes, epidemias, redes de terroristas, criminais e tráfico de drogas), perigos potenciais que afetam a sociedade global. Esta diferenciação potencial tem afetado as sociedades de tal forma que se pode falar de uma sociedade mundial.

Para Brunkhorst, tal sociedade mundial, resultado da diferenciação funcional, divide-se num centro (democracias ocidentais) e periferia (na qual, muitos dos mundos da vida vivem sob constituições "simbólicas" e onde a população está amplamente excluída dos resultados do centro). ${ }^{29}$ Nesse contexto, problemas de inclusão similares aparecem, agora, no nível global: a dessocialização do indivíduo resulta em várias formas de fundamentalismo, guerras civis, etc. E a exclusão social assume a forma

${ }^{28}$ Da perspectiva sociológica: (o problema de) como a sociedade pode ser constituída por indivíduos associados. Da perspectiva normativa: (o problema de) como conciliar liberdade individual com ordem social.

29 Sobre isso, ver: Brunkhorst, Solidarität, 2002, cap. 3; Peripherie und Zentrum in der Weltgeselschaft. Rainer Hampp, 2004; Jenseits von Zentrum und Peripherie. Zur Verfassung der fragmentierten Weltgesellschaft. Rainer Hampp, 2005. 
global. Exclusão que tem gerado uma população global na periferia da sociedade global que está excluída (econômica, social e legalmente), e que se torna supérflua do ponto de vista do centro. Para Brunkhorst, que foi Research Fellow am Maison des Sciences de l'Homme de Paris no ano de 2005, ambos problemas de inclusão apenas podem ser solucionados pela extensão da democracia constitucional.

Mas como estender a democracia para o nível global? Conforme Brunkhorst, dois aspectos são relevantes aqui: a importância de uma esfera pública global e o papel dos direitos humanos.

Tem se tornado visível a emergência de uma esfera pública no nível internacional. Tendências como o incremento de organizações não governamentais e movimentos sociais cujas atividades políticas estendem-se e tornaram possível uma sociedade civil no nível transnacional. Este tipo de atividade seria o começo de uma "globalização da solidariedade civil". No entanto, a esfera pública global não está constitucionalmente autorizada a tomar decisões políticas e, por isso, permanece limitada às políticas de protesto. Por outro lado, ela pode obstruir poder, levantar temas, provocar debates, entre outras coisas. Já a linguagem dos direitos humanos apoia-se nos ganhos no campo da lei internacional, para fazer validar os direitos humanos no nível da lei global. Direitos humanos correspondem aos elementos básicos de uma constituição, eles são o espaço da legitimação democrática que joga um papel importante quando as pessoas não são representadas por aqueles que estão autorizados a tomar decisões. E, na ausência de uma esfera pública global forte, pode-se recorrer aos direitos humanos como recurso para procedimentos democráticos. Atores internacionais podem chamar a atenção, por exemplo, para a violação de direitos políticos, para a situação de pobreza. Estes são alguns dos aspectos que podem ajudar a estabelecer solidariedade civil entre os membros de uma comunidade global gerida pela lei, ou um modo de realizar, no nível global, "o projeto constitucional de 1789". Uma concepção abstrata e legal de sujeitos funciona, aqui, como recurso de solidariedade. Uma forma abstrata de solidariedade entre estranhos, mas entre sujeitos legais que participam de uma comunidade política comum.

É nesse sentido que Brunkhorst desenvolve um conceito de solidariedade baseado na tradição política democrática das sociedades modernas, que tende a ser universalista e que tem, como pano de fundo, a ideia (central para a democracia constitucional moderna) de "direitos humanos", ${ }^{30}$ um conceito de solidariedade democrática

30 Brunkhorst, Recht auf Menschenrecht. Menschenrechte, Demokratie und Internationale Politik. Suhrkamp, 1999; Das Recht der Republik. Suhrkamp, 1999. 
baseado no que é denominado de "patriotismo dos direitos humanos" (Menschenrechtspatriotismus). E, embora o ideal moderno de solidariedade democrática tenha suas origens fincadas na ideia de estado-nação (e isso pode parecer paradoxal, uma vez que "patriotismo" parece referir-se ao estado-nação, enquanto que "direitos humanos" parecem remeter ao universal), a participação poderia ser estendida para além do patriotismo das "repúblicas particulares" para a "república da humanidade".

\section{Referências}

BRUNKHORST, Hauke. Solidarität unter Fremden. Fischer, 1997.

(Ed.). Demokratischer Experimentalismus. Politik in der komplexen Gesellschaft. Frankfurt/M: Suhrkamp, 1998.

(Ed.). Recht auf Menschenrecht. Menschenrechte, Demokratie und Internationale Politik. Frankfurt/M: Suhrkamp, 1999.

KETTNER, Matthias. Globalisierung und Demokratie. Wirtschaft, Recht, Medien. Frankfurt/M: Suhrkamp, 2000.

Globale Solidarität: Inklusionsprobleme der modernen Gesellschaft, W'INGERT, Lutz; GÜNTHER, Klaus. Die Öffentlichkeit der Vernunft und die Vernunft der Öffentlichkeit. Frankfurt/M: Suhrkmp, 2001, p. 605-626.

. Globalising democracy without a State: weak public, strong public, global constitutionalism, Millenium - Journal of International Studies, n.31, 2002, p. 675-690.

. Solidarität. Von der Bürgerfreundschaft zur globalen Rechtsgenossenschaft. Suhrkamp, 2002 [Trad. ingl.: Solidarity. From Civic Friendship to a Global Legal Community. Cambridge/London: MIT Press, 2005].

. Demokratie in der Weltgesellschaft. Hegemoniales Recht, schwache Öffentlichkeit, Menschenrechtspolitik, Bloch-Jahrbuch, 2003, p. 147-162.

. GRÖZINGER, Gerd; MATIASKE, Wenzel. Jenseits von Zentrum und Peripherie. Zur Verfassung der fragmentierten Weltgesellschaft. Rainer Hampp, 2005.

. COSTA, Sérgio. Jenseits von Zentrum und Peripherie. Zur Verfassung der fragmentierten Weltgesellschaft. Rainer Hampp Verlag, 2005.

. Habermas. Reclam, 2006.

. Internationale Verrechtlichung und Demokratie. Zum $60^{\circ}$ Geburstag von Hauke $\overline{B r u n k h o r s t . ~ F r a n k f u r t, ~} 2006$.

. KREIDE, Regina; LAFONT, Cristina. Habermas Handbuch: Leben, Werk, Wirkung. Metzler, 2009.

. Legitimationskrisen. Verfassungsprobleme der Weltgesselschaft. Nomos, 2012.

. Critical Theory of Legal Revolutions. Bloomsbury Academic, 2012.

HABERMAS, Jürgen. Faktizität und Geltung. 4. ed. Frankfurt/M: Suhrkamp, 1994.

. Die Normalität einer Berliner Republik. Frankfurt/M:Suhrkamp, 1995.

. Die Einbeziehung des Anderen. Frankfurt/M: Suhrkamp, 1996. 
HABERMAS, Jürgen. Die postnationale Konstellation. Frankfurt/M: Suhrkamp, 1998. . Zeit der Übergange. Frankfurt/M: Suhrkamp, 2001.

. Zeitdiagnose. Frankfurt/M: Suhrkamp, 2003.

. Der Gespaltene Westen. Frankfurt/M: Suhrkamp, 2004.

. Zwischen Naturalismus und Religion. Frankfurt/M: Suhrkamp, 2005.

. Concluding comments on empirical approaches to deliberative politics, Acta Politica. International Journal of Political Science, 40(3), Sept 2005, p. 384-392.

p. 411-26.

. Political communication in media society. Communication Theory, 16/4 (2006),

Ach, Europa. Frankfurt/M: Suhrkamp, 2008.

. Zur Verfassung Europas. Berlin: Suhrkamp, 2012.

LUBENOW, Jorge Adriano. As críticas de Axel Honneth e Nancy Fraser à filosofia política de Jürgen Habermas, Veritas - Revista de Filosofia (PUCRS), 55(1), 2010, p. 121-134.

. Esfera pública e democracia deliberativa em Habermas: modelo teórico e discursos críticos, Kriterion - Revista de Filosofia (UFMG), n. 121, 2010, p. 227-258.

. A categoria de esfera pública em Jürgen Habermas: para uma reconstrução da autocrítica. João Pessoa: Manufatura, 2012.

. A esfera pública 50 anos depois: esfera pública e meios de comunicação em Jürgen Habermas, Transformação - Revista de Filosofia (UNESP), 35(3), 2012, p. 189-220.

. SILVA, Bartolomeu L. Dossiê esfera pública 50 anos depois. Problemata Revista Internacional de Filosofia (UFPB), 3(2), 2012.

Recebido em 20 de março de 2012.

Aprovado para publicação em 25 de fevereiro de 2013. 